\title{
Mini Review \\ Assessment of endothelial function by flow-mediated dilation in diabetic patients: Effects of physical exercise
}

\author{
Aline P Jarrete \\ Universidade Estadual de Campinas, Campinas, SP, Brasil \\ Angelina Zanesco \\ Universidade Estadual Paulista "Júlio de Mesquita Filho", Rio Claro, SP, Brasil \\ Maria Andréia Delbin \\ Universidade Estadual de Campinas, Campinas, SP, Brasil
}

\begin{abstract}
The endothelium is now recognized as an endocrine organ that acts to maintain vascular homeostasis regulating the vascular tone and structure. The endothelial cells synthetize a variety of mediators among them, the main agent is the nitric oxide (NO), a potent vasodilator. NO exerts its protective role preventing leukocyte adhesion and migration, expression of adhesion molecules, platelet aggregation, cell proliferation, and promoting the relaxation of smooth muscle cells. On the other hand, endothelial dysfunction present in many chronic diseases such as atherosclerosis, coronary artery disease, peripheral artery disease, hypertension and diabetes mellitus, is characterized by reduced NO bioavailability. Thus, a few decades ago, measurement of endothelial function has emerged as valuable tool that provides insights in the pathophysiological mechanisms, opportunity to identify early disease and cardiovascular risk, preventing future events or avoiding the progression of the disease. Diabetic patients, particularly, have been a target to apply this technique, mainly because this condition has been related with an impairment of endothelium-dependent dilation and it is believed that the endothelium dysfunction is the basis of diabetes complications such as coronary artery disease and accelerated atherosclerosis. In addition, cardiovascular complications represent the leading cause of morbidity and death in diabetes mellitus. Besides pharmacological therapy, lifestyle modifications have been recommended by specific organizations as a strategy to improve the endothelial function or even prevent the development of diabetes. The aim of this mini eview is to give an update about the importance of endothelium, most common non-invasive technique to evaluate its function, and to summarize some mechanisms involved in endothelial dysfunction and the beneficial effects of exercise in diabetes mellitus.
\end{abstract}

Keywords: endothelium, diabetes, exercise.

\section{Endothelium}

The blood vessels are mainly constituted by three layers. The outermost layer is called adventitia composed by connective elements (eg. fibroblasts and collagen fibers), nerves ending and perivascular adipose tissue. The medial layer is constituted by smooth muscle which mediates the contraction or dilation of the blood vessels initiated by agonists or mechanical stimulus such as shear stress. The last one and most complex is denominated intimal or endothelium (Ignarro, 1989).

It is well known that vascular endothelium plays a pivotal role in the control of the vascular function and in the vessel morphology; however, this concept emerged over the years. Briefly, in 1800 s, von Reckingausen determined that blood vessels were lined by cells. In 1865, the German anatomist Wilhelm His combined Greek words and proposed the word "endothelium" as complementary term to "epithelium". Currently, there is a consensus to use this word to describe a cell layer that surrounds the entire vascular tree, from the heart to the smallest capillaries and even lymphatic vessels (Favero, Paganelli, Buffoli, Rodella, \& Rezzani, 2014; Thorgeirsson \& Jr, 1978; Zhao, Vanhoutte, \& Leung, 2015).

It well established that endothelium is a monolayer, composed by endothelial cells (ECs), representing an interface between the blood and the vascular wall. Earliest studies believed that ECs have no other functions than the maintenance of permeability to water and electrolytes. In 1950, studies conducted using electron microscopy, provided details and guided in the construction of the current concept of endothelium as a dynamic and active organ with secretory, metabolic and immunologic functions. Another important discovery emerged in 1980, when Furchgott and Zawadzki (1980) demonstrated the obligatory role of ECs presence in the relaxation of blood vessels after acetylcholine stimulation in isolated preparation of rabbit aorta. They demonstrated by the first time that the denuded endothelium (ECs were removed), caused lower relaxing response or even this response could be replaced by a vasoconstriction. They proposed that an endothelium-derived 
relaxing factor might be release from ECs in vascular tissue, later this factor was identified as nitric oxide (Higashi, 2015; Vanhoutte, Shimokawa, Feletou, \& Tang, 2015).

Surprisingly, ECs surface in an adult human, is composed of approximately 1 to $6 \times 10^{13}$ cells and its total length is enough to 2.5 times around the globe. A number of membrane-bound receptors for proteins exist in the ECs, such as growth factors, coagulant, and anticoagulant proteins, lipid transporting particles (eg, low-density lipoprotein), metabolites (eg, serotonin), hormones (eg, endothelin-1). In addition, the angiotensin-converting enzyme is present in the ECs as well as mechanosensors which are for responsible for ECs in detecting mechanical forces and translating in chemical signal governing cell-cell and cell-matrix interactions in vascular system (Cines et al.,1998; Flammer et al., 2012; Rajendran et al., 2013).

Therefore, this intimal layer is not only a structural barrier separating the vessels wall from the circulating blood, but also releases a number of mediators that act in an autocrine and paracrine way to maintain the homeostasis of the cardiovascular system. The exchange of fluid and molecules between blood and tissues, generation of new vascular beds (angiogenesis) and modulation of the immunologic, fibrinolytic and coagulation responses are some of the multiple roles of ECs (Avogaro, Kreutzenberg, \& Fadini, 2008; Cines et al., 1998; Donato, Morgan, Walker, \& Lesniewski, 2015). In addition, ECs play a major role in controlling vascular tone and studies of vasoreactivity is a well known approach used by detecting alterations of ECs and vascular system in some pathological states as well as the modulation of the vascular resistance in response to changes in blood flow in physiological state such as physical exercise (Cines et al., 1998; Avogaro et al., 2008; Delbin \& Trask, 2014; Donato et al., 2015).

Endothelial cells produce and release vasoconstrictors and vasodilators substances and a balance between them is required to maintain vascular homeostasis. The vasoconstriction is mediated mainly by endothelin-1 (ET-1), angiotensin II (ANG II), thromboxane $\mathrm{A} 2\left(\mathrm{TX}_{\mathrm{A} 2}\right)$, prostaglandin $\left(\mathrm{PG}_{\mathrm{H} 2}\right)$ and reactive oxygen species (ROS). The vasodilation effect of ECs is mediated by factors such as nitric oxide (NO), endothelium-derived hyperpolarizing factor (EDHF) and prostacyclin $\left(\mathrm{PG}_{\mathrm{I} 2}\right)$. Although all these mediators have a significant role in the vascular system, NO is considered the most important endothelial-derived factor (Park \& Park, 2015; Vanhoutte et al., 2015).

The NO is a free radical, highly diffusible, and it was the first gaseous molecule to be accepted as a signaling mediator in the organism. NO is produced by three NO synthases (NOS) isoforms using the amino acid L-arginine as a substrate. The neuronal NOS (nNOS or NOS-1) is more expressed in neurons, skeletal muscle, and the NO produced plays a role in the communication between cells. The inducible NOS (iNOS or NOS-2) is expressed in macrophages/monocytes and its induction occurs especially during pathological conditions such as infections and chronic inflammatory diseases. The endothelial NOS (eNOS or NOS-3) is present in the endothelial cells, thus is the major isoform responsible to regulate the vascular system. All these enzymes have similar mechanisms to produce $\mathrm{NO}$, oxidizing the terminal guanidine nitrogen of L-arginine and several cofactors are required including tetrahydrobiopterin - BH4, nicotinamide-adenine-dinucleotide phosphate - NADPH, flavin adenine dinucleotide - FAD, and flavin mononucleotide - FMN) to exert their function (Fleming, 2010; Lundberg, Gladwin, \& Weitzberg, 2015; Zhao et al., 2015).

The eNOS activity is stimulated by various chemical agonists such as acetylcholine, bradykinin and histamine. These substances activate their specific receptors present in the ECs, which in turn, increase the intracellular calcium concentration stimulating the catalytic unit of the enzyme. In a calcium-independent pathway, increased $\mathrm{NO}$ production can also be induced by mechanical stimulus such as shear stress, which induces the phosphorylation of eNOS through the protein kinase A. Particularly, physical exercise is a powerful stimulus to promote vascular shear stress activating mechanosensors. These mechanosensors are coupled to complex biochemical signal pathways, such as Ras/MEK/ERK, c-Src, G proteins, ion channel, VE-cadherin, and PI3K/Akt, which in turn regulate $\mathrm{NO}$ / cGMP pathway (Balligand, Feron, \& Dessy, 2009).

Considered the most potent endogenous vasodilator, NO diffuses from ECs into the underlying smooth muscle cells and activates soluble guanylate cyclase (sGC), which generates the cyclic guanosine monophosphate (cGMP). In the vasculature, this second messenger activates the protein kinase $\mathrm{G}$, promoting the reuptake of cytosolic calcium to the sarcoplasmic reticulum, the extrusion of calcium out of the cell, and the opening of calcium-dependent potassium channels. As a result of these cellular events, there is a decrease in intracellular calcium concentration, promoting the vasodilation. In addition, $\mathrm{NO}$ also acts inhibiting platelet aggregation, leukocyte adhesion, attenuation of vascular smooth muscle cell proliferation and migration, mitochondrial function, oxidative stress and inflammation. Thus, NO is a fundamental protective element to maintain the integrity of endothelium and the homeostasis of the cardiovascular system (Lundberg et al., 2015; Strisciuglio et al., 2014; Versari, Daghini, Virdis, Ghiadoni, \& Taddei, 2009; Zhao et al., 2015).

Given the fundamental role of ECs in vascular biology, different experimental approaches were established to examine endothelium function under physiological and pathological states. In experimental model using different animal species, the endothelium function is evaluated using isolated tissues such as aorta, coronary artery, mesenteric artery and femoral artery. In human trials, the most common approach to assess endothelial function is the flow-mediated dilatation.

\section{Assessment of endothelial function}

Endothelial dysfunction is a condition characterized by loss of the physiological properties of ECs, with impairment of relaxing property and a greater vasoconstrictor response. This unbalance is believed to be as consequence of reduced NO production and/or its bioavailability to the surrounding tissues (Avogaro et al., 2008; Endemann \& Schiffrin, 2004; Strisciuglio et al., 2014). Endothelial dysfunction also causes thromboembolic disease and pro-inflammatory state by NO deficiency. Endothelial dysfunction is implicated in the genesis 
of many chronic diseases including cardiovascular diseases (CVD) including coronary artery disease (CAD), peripheral artery disease (PAD), atherosclerosis, hypertension (HAS), diabetes and chronic kidney disease. Moreover, endothelial dysfunction can be observed in the early stage of CVD, especially atherosclerosis and, has independent prognostic value to acute cardiovascular events for subjects with or without CAD (Halcox et al., 2002; Yang et al., 2010). Thus, early detection of endothelial dysfunction is essential in preventing and even identification of a reversible step in the development of these cardio-metabolic disorders (Park \& Park, 2015; Strisciuglio et al., 2014; Widlansky, Gokce, Keaney Jr., \& Vita, 2003).

Therefore, the development of clinical tests for evaluating the normal or activated properties of endothelium is extremely useful in both clinical and basic research fields (Deanfield, Halcox, \& Rabelink, 2007; Higashi, 2015). As a model of excellence, the tests should be safe, noninvasive, cheap, reproducible, and standardized between research groups. However, no single test currently applied can fill all the proposed requirements (Deanfield et al., 2007). Additionally, all of them have advantages and disadvantages. The principle of the analysis is normal arteries dilate in response to pharmacological stimulus (eg, acetylcholine, bradykinin, or serotonin) or to mechanical stimulus (reactive hyperemia). The dilation response is mainly due the release of NO and other endothelium-derived vasodilator substance, characterizing the endothelium-dependent dilation. On the other hand, exogenous NO donators, such as glycerol-trinitrate, can be administrated to evaluate the endothelium-independent vasodilation, promoting modifications and alterations directly into the smooth muscles cells bypassing endothelium layer (Flammer et al., 2012).

Many endothelium tests have been used to examine endothelium function such as angiography, venous occlusion plethismography, flow-mediated dilatation and peripheral arterial tonometry. However, invasive techniques, especially angiography, are not adequate for investigation of early development of vascular injury in symptom-free subjects and cannot be used a as screening way of general population or for studies with progression and reversibility (Celermajer et al., 1992; Tousoulis, 2005 )preceding formation of plaques. We have devised a non-invasive method for testing endothelial function, to find out whether abnormalities are present in symptom-free children and young adults at high risk of atherosclerosis. With high-resolution ultrasound, we measured the diameter of the superficial femoral and brachial arteries at rest, during reactive hyperaemia (with increased flow causing endothelium-dependent dilatation. On the other hand, flow-mediated dilatation is considered the less invasive and safer for clinical and basic research.

\section{Flow-mediated dilation (FMD)}

David Celejamer and colleagues (1992) developed a non-invasive method, known as flow-mediated dilation (FMD), to evaluate early changes in vascular function in systemic arteries, using a high-resolution ultrasound. It is expressed as a percentage change of the arterial diameter from the baseline diameter
(Corretti et al., 2002; Harris, Nishiyama, Wray, \& Richardson, 2010). FMD has been extensively used in clinical research and it is currently considered a standard for a noninvasive assessment of conduit artery endothelial function (Deanfield et al., 2007; Higashi, 2015). In addition, it was demonstrated a positive correlation between coronary response to acetylcholine and brachial vasodilator response to reactive hyperemia consolidating the use of this method (Anderson et al., 1995).

During the test, vasodilation is usually evaluated in the brachial artery and occurs in response to the significant increase in blood flow, induced by a period of circulatory occlusion. Reactive hyperemia is induced by rapid release of a pneumatic pressure cuff placed around the forearm inflated to suprasystolic pressure for $5 \mathrm{~min}$. This procedure is able to increase shear stress exerted along the vessel, in a parallel and laminar way, activating mechanoreceptors in ECs, promoting the release of NO (Corretti et al., 2002; Harris et al., 2010; Thijssen et al., 2011)hypertension and heart failure. In the 1990s, high-frequency ultrasonographic imaging of the brachial artery to assess endothelium-dependent flow-mediated vasodilation (FMD. Nevertheless, some authors have been stated that the response can not to be only attributed to NO participation (Green, Jones, Thijssen, Cable, \& Atkinson, 2011). Despite being a consolidated method, it requires a great technical skill from investigator, there are no possibilities to correct for measurement-induced change in the systemic hemodynamics because is measured only one arm and; standardization is also a crucial point (Moerland et al., 2012; Widlansky et al., 2003). In addition, it has been pointed out that FMD percentage index can itself generates problems related to baseline diameter-dependency, which can led to biased comparisons of different conditions or populations. It should be emphasized that the researchers had to apply the allometric principles to scale FMD index and improve the interpretation of the protocol and results (Atkinson \& Batterham, 2013, 2015; Atkinson, 2014)albeit with small samples, that the scaling properties of FMD \% can lead to biased inferences on endothelial dysfunction. Therefore, we aimed to investigate the underlying rationale and potential bias of FMD \% using a selection of new examples from the large $(n=3499$. Please see the Figure 1 for more details.

\section{Peripheral arterial tonometry}

Testing endothelial function with peripheral arterial tonometry (PAT) has gained attention as an alternative method to FMD. PAT device (EndoPAT-2000; Itamar Medical, Caesarea, Israel) was originally developed to evaluate vascular changes associated with arousal during sleep and then, applied to vascular reactivity tests by Kuvin and colleagues in 2003 (Bruno, Gori, \& Ghiadoni, 2014; Hamburg \& Benjamin, 2009; Hedetoft \& Olsen, 2014). It consists of finger-mounted probe plethismography used to measure pulsatile arterial volume changes during each pulsation at rest and during reactive hyperemia, due the increase of shear stress. The finger probes contain electronically controllable inflatable chambers, which exert a pressure $(70$ $\mathrm{mmHg}$ ) across the finger, preventing venous pooling and blood 

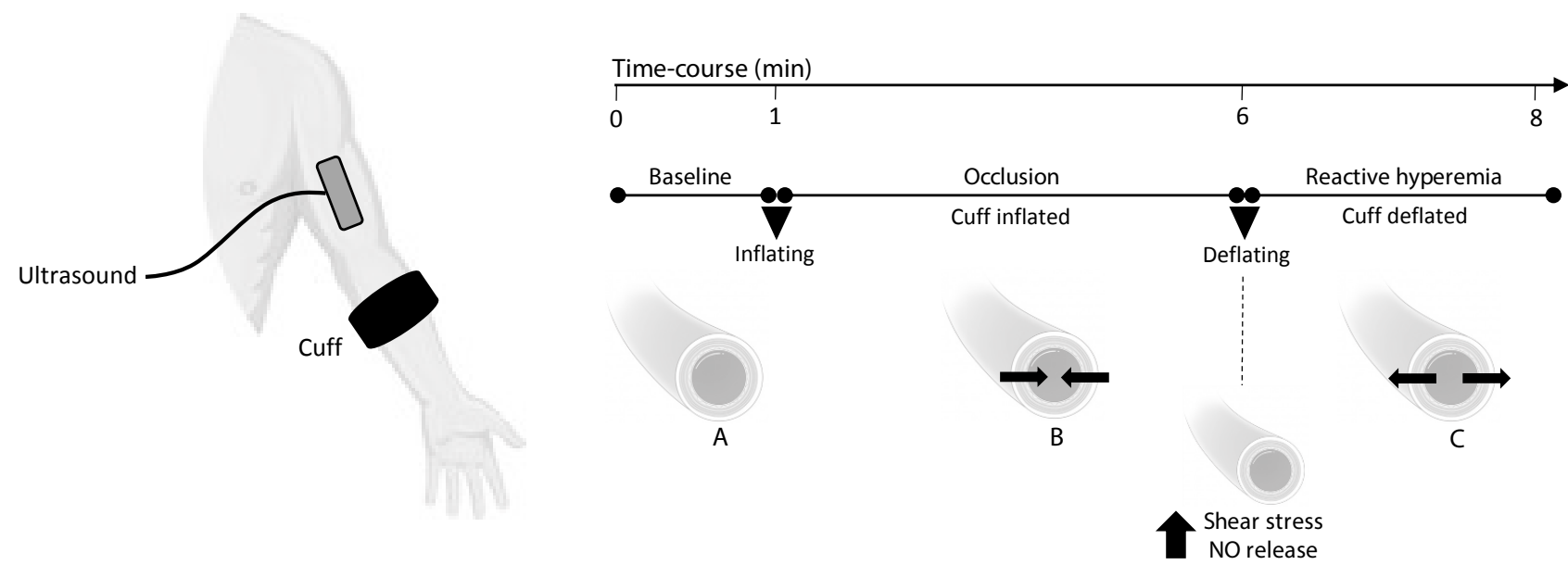

Figure 1. Flow-mediated dilation (FMD) is non-invasive technique using high-resikution ultrasound on the brachial artery composed by three phases. NO: nitric oxide A. After rest time, baseline arterial diameter should be performed. B. The stimulus for the FMD test depends on vascular occlusion period. At this moment, the cuff is inflated above the systolic values for 5 minutes. C. The measurement of arterial diamenter after the cuff release (peak of response between 45 to 60 seconds). characterizing the hyperemic period.

stasis. Moreover, the finger is well perfused and the absence of significant muscle mass facilitates the measurements. PAT examination include three moments including baseline, occlusion (5 minutes) and reactive hyperemia (5 minutes), similar to FMD test. A cuff is placed around the tested arm by reactive hyperemia as well as a finger probe. A second finger probe is placed on the contralateral finger as a control measurement. During the exam, the PAT signal is transmitted to a specific software where will be processed and stored for further analysis (Hedetoft \& Olsen, 2014).

The physiological response to PAT is not completely understood, but it seems to be partly related to NO participation (Nohria et al., 2006). It correlates with FMD of patients with cardiovascular risk factors (Kuvin et al., 2003) and can predict cardiovascular events (Rubinshtein et al., 2010). However, conflicting evidence contesting correlation existence between PAT and FMD have been reported (Allan, Delaney, Miller, \& Spark, 2013; Hamburg et al., 2011; Lind, 2013). For some authors, PAT reflects vasodilator response in microvasculature only, while FMD measures in conduit arteries or macrovasculature, which could justify the absence of correlation between them, depending on the vessel size and location (Dhindsa et al., 2008; Frolow, Drozdz, Kowalewska, Nizankowski, \& Chlopicki, 2015; Hamburg \& Benjamin, 2009; Hamburg et al., 2011). Thus, PAT examination provides a distinct measurement of endothelial function compared with FMD, but it remains a convenient and advantageous technique to evaluate vascular function (Flammer et al., 2012; Hamburg et al., 2011). The main advantages include easy access, operator-independent, automated calculation and controlled by contralateral arm. On the other hand, it is a very expensive approach because finger probes is not reusable, endothelium-independent function is not a reliable measure and is highly influenced by sympathetic tone (Hamburg \& Benjamin, 2009).

\section{Diabetes, endothelial dysfunction and exercise}

Diabetes Mellitus (DM) is a group of metabolic diseases characterized by hyperglycemia due to defects in insulin secretion, action or both. The chronic state of hyperglycemia is associated with damage of several organs, especially eyes, kidneys, heart and blood vessel (American Diabetes Association, 2005). Vascular disease is the main cause of death and morbidity in both type 1 (T1DM) and type 2 (T2DM) diabetes mellitus, affecting small and large vessels (Calles-Escandon \& Cipolla, 2001; Kirpichnikov \& Sowers, 2001). Microvascular complications affect especially nervous system (neuropathy), the retina (retinopathy) and kidneys (nephropathy), while macrovascular disorders affect large vessels that can lead to early myocardial infarctions, ischaemic events, stroke and premature deaths (Harcourt, Penfold, \& Forbes, 2013). Interestingly, glycemic control delays the development of microvascular injuries, but unfortunately, this effect is less pronounced than on the reduction of macrovascular diseases (Rask-Madsen \& King, 2013; Sena, Pereira, \& Seiça, 2013).

Recent studies show that DM doubles the risk of total cardiovascular disease in men, and triples it in women. After adjustment of age, relative risk was higher for women than for men in all complications analyzed which includes congestive heart failure, intermittent claudication, stroke, coronary heart disease, and cardiovascular disease deaths (Qazi \& Malik, 2013).

A large number of evidences suggest that endothelial dysfunction is the main etiological factor for micro and macro vascular complications in DM (Avogaro et al., 2008; CallesEscandon \& Cipolla, 2001). An impairment of endothelium response in experimental model of T1DM (Claudino et al., 2011; Shi \& Vanhoutte, 2008), T2DM (Bunker et al., 2010; Lee, Park, Dellsperger, \& Zhang, 2011), as well as, in clinical studies including both type (Johnstone et al., 1993; Lekakis et 
al., 1997) of diabetic patients (Henry et al., 2004; Williams, Cusco, Roddy \& Johnstone, 1996) have been found. However, in T1DM, metabolic changes related to hyperglycemia seem to be the major trigger for the endothelial dysfunction. Unlike, the relationship between T2DM and impaired endothelial function is more complex because this process starts before the diagnostic of diabetes, with factors such as obesity, dyslipidemia, insulin resistance (Eringa et al., 2013; Sena et al., 2013).

Oxidative stress is a hallmark of diabetic state that contribute to vascular damage. This condition describes an exacerbated ROS production, especially of superoxide, which overcomes the antioxidant defense. All the layer of the blood vessels are able to produce them, and the major source of ROS in vascular tissue seems to be from NADPH oxidase. Another sources of ROS are represented by mitochondria, xanthine oxidase, lipoxygenase and others (Delbin \& Trask, 2014; Rask-Madsen \& King, 2013; Sena et al., 2013). Increased ROS generation are related with abnormalities on structural and functional properties of eNOS by downregulation of phosphoinositide 3-kinase and PI3K/Akt signaling pathway in vascular endothelium; thus, decreasing NO production to the vascular smooth muscle. The adverse effects of this imbalance between oxidant and antioxidant molecules are related with diminished NO bioavailability, formation of peroxynitrite $\left(\mathrm{ONOO}^{-}\right)$and uncoupling of eNOS. (Hwang \& Kim, 2014; Park \& Park, 2015; Toda, Imamura, \& Okamura, 2010).

Hyperglycemia also leads to the modification of extracellular and intracellular proteins resulting in advanced glycation end products (AGEs). In endothelial cells, the interaction between AGEs and their receptor (RAGE) can promote the activation of pro-inflammatory and activation of ROS production signaling pathways (Delbin \& Trask, 2014; Rask-Madsen \& King, 2013). Moreover, it has reported that AGEs modulates negatively the endothelium-dependent relaxation in experimental diabetes (Bucala \& Tracey, 1991). Another alteration in metabolism caused by glucose excess, which account for endothelial dysfunction is related with protein kinase $\mathrm{C}$ (PKC). A ubiquitously expressed enzyme that participates in intracellular signaling. High concentrations of blood glucose causes de novo synthesis of diacylglycerol (DAG) promoting the activation of PKC (De Vriese et al., 2000; Rask-Madsen \& Kahn, 2012). Deleterious effects of this pathway include an increase in expression of ET-1, vascular adhesion molecules (I-CAM / V-CAM), pro-inflammatory cytokines, growth factors, NADPH oxidase activity and at the same time decrease in eNOS activity (Hwang \& Kim, 2014; Roberts \& Porter, 2013). In the same way, it is believed that sorbitol pathway is also responsible for diabetic complications, disrupting the antioxidant defense, activating PKC pathway which results in oxidative stress (Obrosova, 2005). Another consistent mechanisms involved in endothelial dysfunction in the presence of diabetes are the reduction of endothelial progenitor cells (EPCs), endoplasmatic reticulum stress, insulin resistance in vascular cells, alterations in expression of vascular endothelial growth factor (VEGF) and transforming growth factor beta (TGF- $\beta$ ) (Avogaro et al., 2008; Rask-Madsen \& King, 2013).

In an attempt to preserve or to diminish endothelial dysfunction in DM, at least two approaches have been used. A primary therapy, lifestyle modifications for subjects without cardiovascular risk factors whereas in a secondary therapy, the aim is to preserve or improve the function of injured endothelium, avoiding the progression of more damage (Park \& Park, 2015).

Physical exercise is recognized as valuable therapeutic strategy to improve endothelium-dependent dilation in conduit arteries and in the microcirculation and arterial function (Phillips, Mahmoud, Brown, \& Haus, 2015). Thus, lifestyle modifications is crucial for management of DM in children and adults and it has been recommended by American Diabetes Association (Montero, Walther, Benamo, Perez-Martin, \& Vinet, 2013).

Regarding flow-mediated dilation, evidence has shown that FMD is strongly predictive of future cardiovascular events in DM. However, others biomarkers should be examined because some endothelial dysfuction in diabetic patients is not solely related to NO-deficiency. Indeed, recent study found no association between endothelial dysfunction and adults with DM1 and DM2 measured by FMD. According to the authors, this result can be explained by a sophisticated selection of controls groups considering confounders factors such as age, body mass index, smoking and use of antihypertensive drugs (Empen et al., 2013)the validity of this finding may be limited by the lack of adequate adjustment for further cardiovascular confounders. We assessed endothelial function as measured by flow-mediated dilation (FMD. On the other hand, most of studies have shown an increase in forearm blood flow and endothelium dependent dilation after exercise intervention in DM1 and DM2 subjects (de Moraes, Van Bavel, Gomes, \& Tibiriçá, 2016; FuchsjägerMayrl., et al 2002; Kwon et al., 2011; Maiorana et al., 2001). In addition, a meta-analysis including over than 5.000 subjects reported that increased FMD was associated with reduction in the incidence of cardiovascular events (Inaba, Chen, \& Bergmann, 2010). Another recent meta-analysis involving a total of 217 subjects with T2DM, confirmed that exercise training increases nearly $2.23 \%$ the FMD index which can represent the beneficial effect of exercise for this population, preventing cardiovascular complications (Montero et al., 2013). Regarding the time-course of vascular adaptations, the improvement on endothelial function in middle-aged patients with T2DM in response to aerobic exercise training was observed after 2 weeks, and the impact of exercise was preserved after 8 weeks. This finding seems to be a different response compared with healthy subjects and clinically relevant for this population (Schreuder, Green, Nyakayiru, Hopman, \& Thijssen, 2015).

The beneficial effects of exercise training on endothelial function have been attributed to a variety of mechanisms, involving local and systemic factors (Green, 2009). Regarding diabetic condition, programs of exercise structured with at least 8 weeks have a positive impact on glycemic control, and this effect can be independent of weight loss (Boulé, Haddad, Kenny, Wells, 2001). With regards the control of glucose metabolism, a study discussed about the importance of exercise to restore or improve insulin sensitivity that is considered a determinant of the therapeutic action of physical exercise (Phillips et al., 2015).

One of the most significantly consequences of regular exercise is the increase in NO bioavailability (Zanesco \& Antunes, 2007). Both acute and chronic sessions increase the blood flow, 
resulting in augmented shear stress on endothelial cells, which convert the mechanical stimulus in biochemical signals. The immediate effect is the greater release of NO that occurs due to enhanced expression/activity of eNOS or up-regulation of antioxidant enzymes such as superoxide dismutase, catalase and glutathione peroxidase also represents a positive effect of an active lifestyle increasing NO bioavailability. Finally, the reduced expression of oxidant enzymes, mainly NADPH oxidase, favors the reduction of free radicals generation. Together, all these molecular mechanisms, collaborate for diminished NO degradation, improving FMD and/or endothelium function that reflects a a better prognostic for DM (Ashor et al., 2015; Gielen, Schuler, \& Adams, 2010)resistance or combined.

Regarding progenitor endothelial cells, it has been proposed that exercise training stimulates the production of this type of cell by bone marrow that is capable to differentiate into mature endothelial cell (Steiner et al., 2005).

The recommendation of exercise in particular to T2DM is a $150 \mathrm{~min}$ of moderate-to-vigorous intensity of aerobic exercise weekly, in a minimum of 3 days per week. Resistance exercise is an important complement to aerobic exercise since it has been demonstrated that this type of exercise promotes a long lasting effect on blood glucose uptake as compared with aerobic exercise in T1DM patients (Yardley et al., 2013)small studies have found that resistance exercise (weight lifting. The plan of training should respect individuality, based on comorbidities, contraindications and realistic goals (Mendes et al., 2015).

\section{Conclusions}

Advances on assessment of endothelial function in last decades, mainly through the non-invasive techniques have facilitated either basic or clinical researches in cardiovascular and endocrine fields. The developing of flow mediated-dilation method has been a progress allowing to understand the vascular function or dysfunction under different conditions and interventions as well as it is useful to stratify the cardiovascular risk and progression of chronic diseases. However, standardization of methods is a critical point to achieve a valuable prognostic result. In diabetes state, this technique is helping to detect the disease progression and the effects of exercise training on endothelial function according to intensity and duration of practice prescription in clinical trials.

\section{References}

Allan, R. B., Delaney, C. L., Miller, M. D., \& Spark, J. I. (2013). A comparison of flow-mediated dilatation and peripheral artery tonometry for measurement of endothelial function in healthy individuals and patients with peripheral arterial disease. European Journal of Vascular and Endovascular Surgery, 45(3), 263-269. http://doi.org/10.1016/j.ejvs.2012.12.002

American Diabetes Association. (2005). Diagnosis and classification of diabetes mellitus. Diabetes Care. Jan;28 Suppl 1:S37-42.
Anderson, T. J., Uehata, A., Gerhard, M. D., Meredith, I. T., Knab, S., Delagrange, D., ... Yeung, A. C. (1995). Close relation of endothelial function in the human coronary and peripheral circulations. J Am Coll Cardiol, 26(5), 1235-1241. http://doi. org/10.1016/0735-1097(95)00327-4

Ashor, A. W., Lara, J., Siervo, M., Celis-Morales, C., Oggioni, C., Jakovljevic, D. G., \& Mathers, J. C. (2015). Exercise Modalities and Endothelial Function: A Systematic Review and Dose-Response Meta-Analysis of Randomized Controlled Trials. Sports Medicine, 45(2), 279-296. http://doi.org/10.1007/s40279-014-0272-9

Atkinson, G. (2014). Shear rate normalization is not essential for removing the dependency of flow-mediated dilation on baseline artery diameter: past research revisited. Physiological Measurement, 35(9), 1825-1835. http://doi.org/10.1088/0967-3334/35/9/1825

Atkinson, G., \& Batterham, A. M. (2013). The percentage flow-mediated dilation index: a large-sample investigation of its appropriateness, potential for bias and causal nexus in vascular medicine. Vascular Medicine (London, England), 18(6), 354-65. http://doi. org/10.1177/1358863X13508446

Atkinson, G., \& Batterham, A. M. (2015). The clinical relevance of the percentage flow-mediated dilation index. Current Hypertension Reports, 17(2), 4. http://doi.org/10.1007/s11906-014-0514-0

Avogaro, A., Kreutzenberg, S. V. de, \& Fadini, G. (2008). Endothelial dysfunction: causes and consequences in patients with diabetes mellitus. Diabetes Research and Clinical Practice, 82 Suppl 2, 94-S101. http://doi.org/10.1016/j.diabres.2008.09.021

Balligand, J., Feron, O., \& Dessy, C. (2009). eNOS Activation by Physical Forces : From Short-Term Regulation of Contraction to Chronic Remodeling of Cardiovascular Tissues, 481-534. http:// doi.org/10.1152/physrev.00042.2007.

Boulé NG, Haddad E, Kenny GP, Wells GA, S. R. (2001). Effects of exercise on glycemic control and body mass in type 2 diabetes mellitus: A meta-analysis of controlled clinical trials. Jama, 286(10), 1218-1227. Retrieved from http://dx.doi.org/10.1001/ jama.286.10.1218

Bruno, R. M., Gori, T., \& Ghiadoni, L. (2014). Endothelial function testing and cardiovascular disease: focus on peripheral arterial tonometry. Vascular Health and Risk Management, 10, 577-84. http://doi.org/10.2147/VHRM.S44471

Bucala R, Tracey KJ, C. a. (1991). Advanced glycosylation produces quench nitric oxide and mediate defective endothelium-dependent vasodilation in experimental diabetes. $J$ Clin Invest, 87(2), 432-438. http://doi.org/10.1172/JCI115014

Bunker, A. K., Arce-Esquivel, A. A., Rector, R. S., Booth, F. W., Ibdah, J. A., \& Laughlin, M. H. (2010). Physical activity maintains aortic endothelium-dependent relaxation in the obese type 2 diabetic OLETF rat. American Journal of Physiology. Heart and Circulatory Physiology, 298(6), H1889-901. http://doi. org/10.1152/ajpheart.01252.2009

Calles-Escandon, J., \& Cipolla, M. (2001). Diabetes and Endothelial Dysfunction: A Clincial Perspective. Endocrine Reviews, 22(February), 36-52.

Celermajer, D. S., Sorensen, K. E., Gooch, V. M., Spiegelhalter, D. J., Miller, O. I., Sullivan, I. D., ... Deanfield, J. E. (1992). Noninvasive detection of endothelial dysfunction in children and adults at risk of atherosclerosis. Lancet, 340(8828), 1111-1115. http://doi. org/10.1016/0140-6736(92)93147-F 
Cines, B. D. B., Pollak, E. S., Buck, C. A., Loscalzo, J., Zimmerman, G. A., Mcever, R. P., ... Stern, D. M. (1998). The Journal of The American Society of Hematology, 91(10), 3527-3561.

Claudino, M. A., Delbin, M. A., Franco-Penteado, C. F., Priviero, F. B., De Nucci, G., Antunes, E., \& Zanesco, A. (2011). Exercise training ameliorates the impairment of endothelial and nitrergic corpus cavernosum responses in diabetic rats. Life Sciences, $88(5-$ 6), 272-277. http://doi.org/10.1016/j.lfs.2010.11.018

Corretti, M. C., Anderson, T. J., Benjamin, E. J., Celermajer, D., Charbonneau, F., Creager, M. A., ... Vogel, R. (2002). Guidelines for the ultrasound assessment of endothelial-dependent flow-mediated vasodilation of the brachial artery: a report of the International Brachial Artery Reactivity Task Force. Journal of the American College of Cardiology, 39(2), 257-65. http://doi.org/10.1016/ S0735-1097(01)01746-6

de Moraes, R., Van Bavel, D., Gomes, M. de B., \& Tibiriçá, E. (2016). Effects of non-supervised low intensity aerobic excise training on the microvascular endothelial function of patients with type 1 diabetes: a non-pharmacological interventional study. $B M C$ Cardiovascular Disorders, 16(1), 23. http://doi.org/10.1186/ s12872-016-0191-9

De Vriese, a. S. S., Verbeuren, T. J. T. J. J., Van de Voorde, J., Lameire, N. H. N. H. H., Vanhoutte, P. M. P. M., Van V, D., .. Voorde, J. Van De. (2000). Endothelial dysfunction in diabetes. Br.J.Pharmacol., 130(5), 963-974. http://doi.org/10.1038/sj.bjp.0703393

Deanfield, J. E., Halcox, J. P., \& Rabelink, T. J. (2007). Endothelial function and dysfunction: Testing and clinical relevance. Circulation, 115(10), 1285-1295. http://doi.org/10.1161/ CIRCULATIONAHA.106.652859

Delbin, M. A., \& Trask, A. J. (2014). The diabetic vasculature: Physiological mechanisms of dysfunction and influence of aerobic exercise training in animal models. Life Sciences, 102(1), 1-9. http://doi.org/10.1016/j.lfs.2014.02.021

Dhindsa, M., Sommerlad, S. M., DeVan, A. E., Barnes, J. N., Sugawara, J., Ley, O., \& Tanaka, H. (2008). Interrelationships among noninvasive measures of postischemic macro- and microvascular reactivity. J Appl Physiol, 105, 427-432. http://doi.org/90431.2008 [pii] \r10.1152/japplphysiol.90431.2008

Donato, A. J., Morgan, R. G., Walker, A. E., \& Lesniewski, L. a. (2015). Cellular and molecular biology of aging endothelial cells. Journal of Molecular and Cellular Cardiology, 1-14. http://doi. org/10.1016/j.yjmcc.2015.01.021

Empen, K., Lorbeer, R., Völzke, H., Reffelmann, T., Schipf, S., Nauck, M., ... Dörr, M. (2013). Do patients with type 1 and type 2 diabetes really have an impaired endothelial function? A population-based propensity score matching analysis. Cardiovascular Diabetology, 12, 174. http://doi.org/10.1186/1475-2840-12-174

Endemann, D. H., \& Schiffrin, E. L. (2004). Nitric oxide, oxidative excess, and vascular complications of diabetes mellitus. Current Hypertension Reports, 6(2), 85-9. http://doi.org/10.1007/ s11906-004-0081-X

Eringa, E. C., Serne, E. H., Meijer, R. I., Schalkwijk, C. G., Houben, A. J. H. M., Stehouwer, C. D. a, ... van Hinsbergh, V. W. M. (2013). Endothelial dysfunction in (pre)diabetes: characteristics, causative mechanisms and pathogenic role in type 2 diabetes. Reviews in Endocrine \& Metabolic Disorders, 14(1), 39-48. http:// doi.org/10.1007/s11154-013-9239-7
Favero, G., Paganelli, C., Buffoli, B., Rodella, L. F., \& Rezzani, R. (2014). Endothelium and its alterations in cardiovascular diseases: life style intervention. BioMed Research International, 2014, 801896. http://doi.org/10.1155/2014/801896

Flammer, A. J., Anderson, T., Celermajer, D. S., Creager, M. A., Deanfield, J., Ganz, P., ... Lerman, A. (2012). The Assessment of Endothelial Function: From Research Into Clinical Practice. Circulation, 126(6), 753-767. http://doi.org/10.1161/ CIRCULATIONAHA.112.093245

Fleming, I. (2010). Molecular mechanisms underlying the activation of eNOS. Pflugers Archiv European Journal of Physiology, 459(6), 793-806. http://doi.org/10.1007/s00424-009-0767-7

Frolow, M., Drozdz, A., Kowalewska, A., Nizankowski, R., \& Chlopicki, S. (2015). Comprehensive assessment of vascular health in patients; towards endothelium-guided therapy. Pharmacological Reports, 67(4), 786-792. http://doi. org/10.1016/j.pharep.2015.05.010

Fuchsjäger-Mayrl G, Pleiner J, Wiesinger GF, Sieder AE, Quittan M, N. M., \& Francesconi C, Seit HP, Francesconi M, Schmetterer L, W. M. (2002). Endothelial Function in Patients with Type 1 Diabetes, 25(10).

Gielen, S., Schuler, G., \& Adams, V. (2010). Cardiovascular effects of exercise training: Molecular mechanisms. Circulation, 122(12), 12211238. http://doi.org/10.1161/CIRCULATIONAHA.110.939959

Green, D. J. (2009). Exercise training as vascular medicine: direct impacts on the vasculature in humans. Exercise and Sport Sciences Reviews, 37(10), 196-202. http://doi.org/10.1097/ JES.0b013e3181b7b6e3

Green, D. J., Jones, H., Thijssen, D., Cable, N. T., \& Atkinson, G. (2011). Flow-Mediated Dilation and Cardiovascular Event Prediction: Does Nitric Oxide Matter? Hypertension, 57(3), 363369. http://doi.org/10.1161/HYPERTENSIONAHA.110.167015

Halcox, J. P. J., Schenke, W. H., Zalos, G., Mincemoyer, R., Prasad, A., Waclawiw, M. A., ... Quyyumi, A. A. (2002). Prognostic value of coronary vascular endothelial dysfunction. Circulation, 106(6), 653-658. http://doi.org/10.1161/01.CIR.0000025404.78001.D8

Hamburg, N. M., \& Benjamin, E. J. (2009). Assessment of Endothelial Function Using Digital Pulse Amplitude Tonometry. Trends in Cardiovascular Medicine, 19(1), 6-11. http://doi.org/10.1016/j. tcm.2009.03.001

Hamburg, N. M., Palmisano, J., Larson, M. G., Sullivan, L. M., Lehman, B. T., Vasan, R. S., ... Benjamin, E. J. (2011). Relation of Brachial and Digital Measures of Vascular The Framingham Heart Study. http://doi.org/10.1161/HYPERTENSIONAHA.110.160812

Harcourt, B. E., Penfold, S. a, \& Forbes, J. M. (2013). Coming full circle in diabetes mellitus: from complications to initiation. Nature Reviews. Endocrinology, 9(2), 113-23. http://doi.org/10.1038/ nrendo.2012.236

Harris, R. A., Nishiyama, S. K., Wray, D. W., \& Richardson, R. S. (2010). Ultrasound assessment of flow-mediated dilation. Hypertension, 55(5), 1075-1085. http://doi.org/ HYPERTENSIONAHA.110.150821

Hedetoft, M., \& Olsen, N. V. (2014). Evaluation of endothelial function by peripheral arterial tonometry and relation with the nitric oxide pathway. Nitric Oxide : Biology and Chemistry / Official Journal of the Nitric Oxide Society, 42, 1-8. http://doi.org/10.1016/j. niox.2014.07.003 
Henry, R. M. A., Ferreira, I., Kostense, P. J., Dekker, J. M., Nijpels, G., Heine, R. J., ... Stehouwer, C. D. A. (2004). Type 2 diabetes is associated with impaired endothelium-dependent, flow-mediated dilation, but impaired glucose metabolism is not: The Hoorn Study. Atherosclerosis, 174(1), 49-56. http://doi.org/10.1016/j. atherosclerosis.2004.01.002

Higashi, Y. (2015). Assessment of endothelial function. History, methodological aspects, and clinical perspectives. International Heart Journal, 56(2), 125-134. http://doi.org/10.1536/ihj.14-385

Hwang, M.-H., \& Kim, S. (2014). Type 2 Diabetes: Endothelial dysfunction and Exercise. Journal of Exercise Nutrition \& Biochemistry, 18(3), 239-47. http://doi.org/10.5717/jenb.2014.18.3.239

Ignarro, L. J. (1989). Endothelium-derived and properties nitric oxide : actions and properties. FASEB Journal, 3, 31-36.

Inaba, Y., Chen, J. A., \& Bergmann, S. R. (2010). Prediction of future cardiovascular outcomes by flow-mediated vasodilatation of brachial artery: A meta-analysis. International Journal of Cardiovascular Imaging, 26(6), 631-640. http://doi.org/10.1007/ s10554-010-9616-1

Johnstone, M. T., Creager, S. J., Scales, K. M., Cusco, J. A., Lee, B. K., \& Creager, M. A. (1993). Impaired Endothelium-Dependent Vasodilation in Patients With Insulin-Dependent Diabetes Mellitus, 2510-2517.

Kirpichnikov, D., \& Sowers, J. R. (2001). Diabetes mellitus and diabetes-associated vascular disease. Trends in Endocrinology and Metabolism: TEM, 12(5), 225-30. http://doi.org/10.1016/ S1043-2760(01)00391-5

Kuvin, J. T., Patel, A. R., Sliney, K. A., Pandian, N. G., Sheffy, J., Schnall, R. P., ... Udelson, J. E. (2003). Assessment of peripheral vascular endothelial function with finger arterial pulse wave amplitude. American Heart Journal, 146(1), 168-174. http://doi. org/10.1016/S0002-8703(03)00094-2

Kwon, H. R., Min, K. W., Ahn, H. J., Seok, H. G., Lee, J. H., Park, G. S., \& Han, K. A. (2011). Effects of Aerobic Exercise vs. Resistance Training on Endothelial Function in Women with Type 2 Diabetes Mellitus. Diabetes \& Metabolism Journal, 35(4), 364-73. http:// doi.org/10.4093/dmj.2011.35.4.364

Lee, S., Park, Y., Dellsperger, K. C., \& Zhang, C. (2011). Exercise training improves endothelial function via adiponectin-dependent and independent pathways in type 2 diabetic mice, (29), 306-314. http://doi.org/10.1152/ajpheart.01306.2010.

Lekakis, J., Papamichael, C., Anastasiou, H., Alevizaki, M., Desses, N., Souvatzoglou, A., ... Koutras, D. A. (1997). Endothelial dysfunction of conduit arteries in insulin-dependent diabetes mellitus without microalbuminuria. Cardiovascular Research, 34(1), 164-168. http://doi.org/10.1016/S0008-6363(97)00015-1

Lind, L. (2013). Relationships between three different tests to evaluate endothelium-dependent vasodilation and cardiovascular risk in a middle-aged sample. Journal of Hypertension, 31(8), 1570-4. http://doi.org/10.1097/HJH.0b013e3283619d50

Lundberg, J. O., Gladwin, M. T., \& Weitzberg, E. (2015). Strategies to increase nitric oxide signalling in cardiovascular disease. Nature Reviews Drug Discovery, 14(9), 623-641. http://doi.org/10.1038/ $\operatorname{nrd} 4623$

Maiorana, A., O’Driscoll, G., Cheetham, C., Dembo, L., Stanton, K., Goodman, C., ... Green, D. (2001). The effect of combined aerobic and resistance exercise training on vascular function in type 2 diabetes. Journal of the American College of Cardiology, 38(3), 860-866. http://doi.org/10.1016/S0735-1097(01)01439-5

Mendes, R., Sousa, N., Almeida, A., Subtil, P., Guedes-Marques, F., Reis, V. M., \& Themudo-Barata, J. L. (2015). Exercise prescription for patients with type 2 diabetes - a synthesis of international recommendations: narrative review. British Journal of Sports Medicine, 0, 1-4. http://doi.org/10.1136/bjsports-2015-094895

Moerland, M., Kales, A. J., Schrier, L., Dongen, M. G. J. Van, Bradnock, D., Burggraaf, J., ... Burggraaf, J. (2012). Evaluation of the EndoPAT as a Tool to Assess Endothelial Function. International Journal of Vascular Medicine, 2012, 904141. http:// doi.org/10.1155/2012/904141

Montero, D., Walther, G., Benamo, E., Perez-Martin, a, \& Vinet, a. (2013). Effects of exercise training on arterial function in type 2 diabetes mellitus: a systematic review and meta-analysis. Sports Med, 43(11), 1191-1199. http://doi.org/10.1007/ s40279-013-0085-2

Nohria, A., Gerhard-Herman, M., Creager, M. a, Hurley, S., Mitra, D., \& Ganz, P. (2006). Role of nitric oxide in the regulation of digital pulse volume amplitude in humans. Journal of Applied Physiology (Bethesda, Md. : 1985), 101(2), 545-548. http://doi.org/10.1152/ japplphysiol.01285.2005

Obrosova, I. G. (2005). Increased sorbitol pathway activity generates oxidative stress in tissue sites for diabetic complications. Antioxidants \& Redox Signaling, 7(c), 1543-1552. http://doi. org/10.1089/ars.2005.7.1543

Park, K., \& Park, W. J. (2015). Endothelial Dysfunction : Clinical Implications in Cardiovascular Disease and Therapeutic Approaches. J Korean Med Sci, 30, 1213-1225. http://doi. org/10.3346/jkms.2015.30.9.1213

Phillips, S. A., Mahmoud, A. M., Brown, M. D., \& Haus, J. M. (2015). Exercise interventions and peripheral arterial function: Implications for cardio-metabolic disease. Progress in Cardiovascular Diseases, 57(5), 521-534. http://doi.org/10.1016/j.pcad.2014.12.005

Qazi, M. U., \& Malik, S. (2013). Diabetes and Cardiovascular Disease: Original Insights from the Framingham Heart Study. Global Heart, 8(1), 43-48. http://doi.org/10.1016/j.gheart.2012.12.008

Rajendran, P., Rengarajan, T., Thangavel, J., Nishigaki, Y., Sakthisekaran, D., Sethi, G., \& Nishigaki, I. (2013). The Vascular Endothelium and Human Diseases. International Journal of Biological Sciences, 9(10), 1057-1069. http://doi.org/10.7150/ ijbs. 7502

Rask-Madsen, C., \& Kahn, C. R. (2012). Tissue-Specific Insulin Signaling, Metabolic Syndrome, and Cardiovascular Disease. Arteriosclerosis, Thrombosis, and Vascular Biology, 32(9), 2052-2059. http://doi.org/10.1161/ATVBAHA.111.241919

Rask-Madsen, C., \& King, G. L. (2013). Vascular Complications of Diabetes: Mechanisms of Injury and Protective Factors. Cell Metabolism, 17(1), 20-33. http://doi.org/10.1016/j. cmet.2012.11.012

Roberts, A. C., \& Porter, K. E. (2013). Cellular and molecular mechanisms of endothelial dysfunction in diabetes. Diabetes and Vascular Disease Research, 10(6), 472-482. http://doi. org/10.1177/1479164113500680

Rubinshtein, R., Kuvin, J. T., Soffler, M., Lennon, R. J., Lavi, S., Nelson, R. E., ... Lerman, A. (2010). Assessment of endothelial function by non-invasive peripheral arterial tonometry predicts late 
cardiovascular adverse events. European Heart Journal, 31(9), 1142-1148. http://doi.org/10.1093/eurheartj/ehq010

Schreuder, T. H. A., Green, D. J., Nyakayiru, J., Hopman, M. T. E., \& Thijssen, D. H. J. (2015). Time-course of vascular adaptations during 8 weeks of exercise training in subjects with type 2 diabetes and middle-aged controls. European Journal of Applied Physiology, 115(1), 187-196. http://doi.org/10.1007/s00421-014-3006-7

Sena, C. M., Pereira, A. M., \& Seiça, R. (2013). Endothelial dysfunction - A major mediator of diabetic vascular disease. Biochimica et Biophysica Acta (BBA) - Molecular Basis of Disease, 1832(12), 2216-2231. http://doi.org/10.1016/j.bbadis.2013.08.006

Shi, Y., \& Vanhoutte, P. (2008). Oxidative stress and COX cause hyper-responsiveness in vascular smooth muscle of the femoral artery from diabetic rats. British Journal of Pharmacology, 154(December 2007), 639-51. http://doi.org/10.1038/bjp.2008.110

Steiner, S., Niessner, A., Ziegler, S., Richter, B., Seidinger, D., Pleiner, J., ... Kopp, C. W. (2005). Endurance training increases the number of endothelial progenitor cells in patients with cardiovascular risk and coronary artery disease. Atherosclerosis, 181(2), 305-310. http://doi.org/10.1016/j.atherosclerosis.2005.01.006

Strisciuglio, T., De Luca, S., Capuano, E., Luciano, R., Niglio, T., Trimarco, B., \& Galasso, G. (2014). Endothelial dysfunction: Its clinical value and methods of assessment. Current Atherosclerosis Reports, 16(6), 1-7. http://doi.org/10.1007/s11883-014-0417-1

Thijssen, D. H. J., Black, M. a, Pyke, K. E., Padilla, J., Atkinson, G., Harris, R. a, ... Green, D. J. (2011). Assessment of flow-mediated dilation in humans: a methodological and physiological guideline. American Journal of Physiology. Heart and Circulatory Physiology, 300(1), H2-H12. http://doi.org/10.1152/ajpheart.01158.2010

Thorgeirsson, G., \& Jr, A. R. (1978). The vascular endothelium-pathobiologic significance. The American Journal of Pathology, 93(3), 803-848. Retrieved from http://www.ncbi.nlm.nih.gov/pmc/ articles/PMC2018350/

Toda, N., Imamura, T., \& Okamura, T. (2010). Alteration of nitric oxide-mediated blood flow regulation in diabetes mellitus. Pharmacology \& Therapeutics, 127(3), 189-209. http://doi. org/10.1016/j.pharmthera.2010.04.009

Tousoulis, D. (2005). Evaluating endothelial function in humans: a guide to invasive and non-invasive techniques. Heart, 91(4), 553-558. http://doi.org/10.1136/hrt.2003.032847

Vanhoutte, P. M., Shimokawa, H., Feletou, M., \& Tang, E. H. C. (2015). Endothelial Dysfunction and Vascular Disease - A Thirthieth Anniversary Update. Acta Physiologica, n/a-n/a. http://doi. org/10.1111/apha.12646

Versari, D., Daghini, E., Virdis, A., Ghiadoni, L., \& Taddei, S. (2009). Endothelial Dysfunction as a Target for Prevention of Cardiovascular Disease. Diabetes Care, 32(suppl_2), S314-S321. http://doi.org/10.2337/dc09-S330

Widlansky, M. E., Gokce, N., Keaney Jr., J. F., \& Vita, J. A. (2003). The clinical implications of endothelial dysfunction. J Am Coll Cardiol, 42(7), 1149-1160. http://doi.org/10.1016/s0735-1097(03)00994-x

Williams SB, Cusco JA, Roddy MA, Johnstone MT, C. M. (1996). Impaired nitric oxide-mediated vasodilation in patients with non-insulin-dependent diabetes mellitus. J Am Coll Cardiol, 27(22), 567-74.

Yang, G., Lucas, R., Caldwell, R., Yao, L., Romero, M. J., \& Caldwell, R. W. (2010). Novel mechanisms of endothelial dysfunction in diabetes. Journal of Cardiovascular Disease Research, 1(2), 59-63. http://doi.org/10.4103/0975-3583.64432

Yardley, J. E., Kenny, G. P., Perkins, B. A., Riddell, M. C., Balaa, N., Malcolm, J., ... Sigal, R. J. (2013). Resistance versus aerobic exercise. Diabetes Care, 36(3), 537-542. http://doi.org/10.2337/ dc12-0963

Zanesco, A., \& Antunes, E. (2007). Effects of exercise training on the cardiovascular system: pharmacological approaches. Pharmacology \& Therapeutics, 114(3), 307-317. http://doi. org/10.1016/j.pharmthera.2007.03.010

Zhao, Y., Vanhoutte, P. M., \& Leung, S. W. S. (2015). Vascular nitric oxide: Beyond eNOS. Journal of Pharmacological Sciences, 129(2), 83-94. http://doi.org/10.1016/j.jphs.2015.09.002

Corresponding author:

Maria Andréia Delbin, Assistant Professor

Laboratory of Vascular Biology

Email: madelbin@unicamp.br

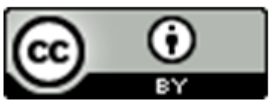

Motriz. The Journal of Physical Education. UNESP. Rio Claro, SP, Brazil - eISSN: 1980-6574 - under a license Creative Commons - Version 3.0 